\title{
Spray Conditioning for the Preparation of Spray Dried Submicron Particles
}

\author{
Ramona Gorny*, Gerhard Schaldach, Peter Walzel, Markus Thommes \\ Laboratory of Solids Process Engineering, TU Dortmund University, Germany \\ ${ }^{*}$ Corresponding author: ramona.gorny@bci.tu-dortmund.de
}

\begin{abstract}
Particle size reduction down to the submicron range $(0.1-1 \mu \mathrm{m})$ is an effective option to increase the bioavailability of low water soluble active pharmaceutical ingredients. According to the Nernst-Brunner equation, the preparation of submicron sized particles increases the specific surface area, thus increases the dissolution rate. Conventional spray drying devices for submicron particles show certain limitations. The main challenge is the preparation of small and uniform droplets during the atomisation step. In this work, fine droplets were generated combining a nozzle with a droplet separator. Therefore, the aerosol is generated with a pneumatic nozzle and is sprayed into a cyclone droplet separator. Depending on the characteristics of the cyclone, droplets larger than the cut-off-size were separated and returned into the liquid feed. The conditioned aerosol at the top of the cyclone separator can then be introduced into the drying chamber. With this concept the usable part is separated, thus no classification process after drying is necessary. The investigations show that the dependencies during atomisation of the droplets size on the liquid-to-gas mass flow ratio $\mu_{m}$ and the liquid properties (e.g. viscosity) do not apply to the separation step. The conditioned aerosol only depends on the separation characteristics of the cyclone droplet separator. However, the amount of droplets separated is determined by the atomisation step. Hence, the amount of droplets smaller than the cut-off-size can be increased by decreasing the droplet size of the primary aerosol. This is realised by secondary droplet fragmentation. An impact surface causes breakup of the droplets of the primary aerosol before separation. The investigations show an increased amount of droplets $<2 \mu m$.
\end{abstract}

\section{Keywords}

spray drying, low water soluble drugs, submicron particles, droplet fragmentation

\section{Introduction}

The preparation of particles down to the submicron scale $(0.1-1 \mu \mathrm{m})$ obtains much attention in many different application fields, since their chemical or physical behavior differs compared to bulk forms [1]. For pharmaceutical application a high amount of newly identified active pharmaceutical ingredients show low water solubility and therefore exhibit low bioavailability [2]. So far, different strategies were developed (physical or chemical modification) to ensure pharmacological response [3]. This work focuses on physical modification. For low water soluble drugs, the bioavailability may be limited by the dissolution rate, which can be described by the NernstBrunner equation [4,5]:

$\frac{d m}{d t}=A \cdot \frac{D}{h} \cdot\left(c_{s}-c\right)$

The increase in the specific surface area directly increases the dissolution rate $d m / d t$, thus increases the bioavailability. Next to the dissolution rate, for particles down to $1 \mu \mathrm{m}$, solubility is a function of particle size. The relation between particle size and solubility is described by the Ostwald-Freundlich equation [6]:

$c_{s}=c_{s}^{\infty} \cdot \exp \left(\frac{2 \gamma M}{r \rho R T}\right)$

Thus, particle size reduction below $1 \mu \mathrm{m}$ will lead to increased saturation concentration $c_{s}$ for nanosized particles. Up to this point, different submicron particle preparation methods were developed, which can be divided into topdown and bottom-up techniques. For top-down methods, the particle size is reduced by milling or high-pressure homogenization. In bottom-up approaches, the particles were generated by precipitation or evaporation from a bulk solution. Spray drying is a bottom-up technique where the solution is initially atomised into fine droplets in a drying chamber. The dried particles are separated usually by a cyclone. Spray drying enables the generation of particles in a single step, where particle size, morphology and shape can be adjusted by the spray drying conditions. For submicron sized particles, conventional spray drying processes show limitations. This includes the separation of particles with cyclones, since they are not suitable for submicron particles. [3] 
One major challenge is the atomisation step. The particle size is mainly defined by the droplets size, thus small and uniform droplets $d<3 \mu m$ are crucial. With an estimate of limits including small geometric dimensions of the nozzle and water properties, the smallest mean droplet size for conventional pneumatic nozzle is limited at about $5 \mu \mathrm{m}$. [7]

The main concept for a robust process to generate small and uniform droplets includes the separation of the suitable part of the aerosol by using a cyclone droplet separator. A pneumatic nebulizer with internal mixing is used to produce the aerosol. During aerosol conditioning the aerosol is sprayed into a cyclone. The droplet separator was designed with regard to generate a small cut-off size with $d_{\text {cut-off }}=2.6 \mu \mathrm{m}$ during separation. The experimental setup and an image of the designed cyclone [8] are presented in Figure 1.

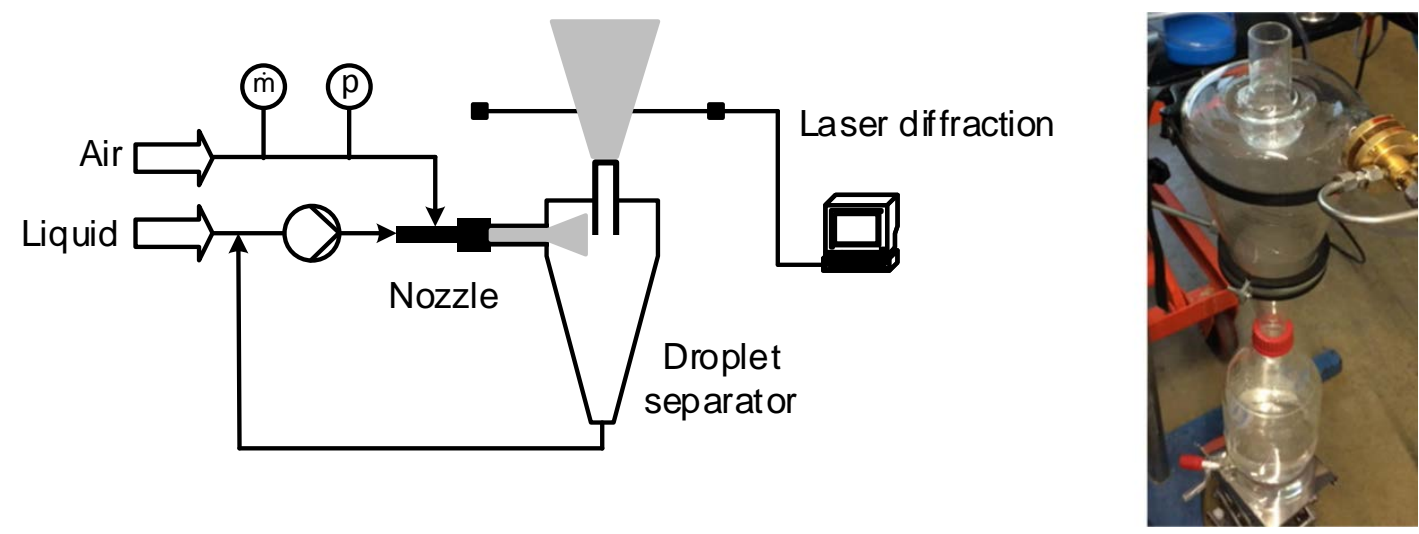

Figure 1: Left: Setup for aerosol conditioning for the generation of small and uniform droplets. Right: Image of the cyclone droplet separator in combination with a pneumatic nozzle

Droplets larger the cut-off size were separated and returned back to the liquid feed. With the designed droplet separator, only the desired part of the aerosol is introduced into the drying chamber. First experiments were carried out with a $10 \mathrm{wt}$ - $\%$ mannitol solution for different liquid-to-gas-mass flow ratios $\mu_{m}=\frac{\dot{m}_{L}}{\dot{m}_{G}}$ and a Povidone $\mathrm{K}$ 30 solution with different viscosities. The conditioned aerosol shows a constant mean droplet size for different liquid-to-gas mass flow ratios and viscosities. Thus, the droplet size of the conditioned aerosol only depends on the separation characteristics of the cyclone with low sensitivity to the flow rate. Hence, this concept is robust regarding high concentrations or viscosities and is able to handle fluctuations of the spraying device. First drying experiments confirm the generation of submicron sized mannitol particles [8].

After drying, the product yield of dried particles is mainly limited by the amount of small droplets, generated by the pneumatic nozzle. With the current setup, the yield of the conditioned aerosol was only about $1 \%$. Therefore, an impact sphere is positioned at a specific distance in front of the nozzle orifice to cause a break up of too large droplets. The collision process of a droplet on a dry or wetted surface is analyzed manifold [9-11]. The required collision velocity for droplet fragmentation with a wetted surface can be estimated according to experimental results [10] with equation 3 :

$v=50 \cdot d_{0}^{-0.6} \cdot \rho^{-0.6} \eta^{0.2} \gamma^{0.4}$

For a droplet size of about $10 \mu \mathrm{m}$ and liquid properties of water an impact velocity of $70 \mathrm{~m} / \mathrm{s}$ is necessary. The droplet size distribution of the aerosol resulting from additional fragmentation will now be discussed.

With a subsequent droplet separator, bigger droplets are removed and a combination with a drying step is possible.

\section{Material and methods}

\section{Aerosol fragmentation with an impact sphere}

Again, the aerosol is firstly generated with a pneumatic internal mixing nozzle. The liquid is dispersed into the gas flow by seven capillaries with an inner capillary diameter of $d_{c a p}=0.5 \mathrm{~mm}$. Deionised water was pumped with a HPLC pump (80P, KNAUER, Berlin, Germany) and sprayed with compressed air. The mass flow of compressed air was measured with a flow meter (Model D10A11, ABB, Göttingen, Germany) and the gas inlet pressure was read on a manometer. For all experiments, the gas inlet pressure was held constant and the self-regulating gas mass flow was measured $\left(\dot{m}_{G}=4.3-4.8 \mathrm{~kg} / \mathrm{h}\right)$. The liquid mass flow rate was varied between 
$\dot{m}_{L}=1.2-3 \mathrm{~kg} / \mathrm{h}\left(\dot{V}_{L}=20-50 \mathrm{~mL} / \mathrm{min}\right)$ and the liquid-to-gas mass flow ratio $\mu_{\mathrm{m}}$ ranged between $0.24-0.70$. The experimental setup for spray fragmentation is presented in Figure 2. For the fragmentation of the aerosol, a sphere with the diameter $d_{s}=7 \mathrm{~mm}$ is located in front of the nozzle orifice $D_{o}=1 \mathrm{~mm}$ at a distance $L=5 \mathrm{~mm}$.

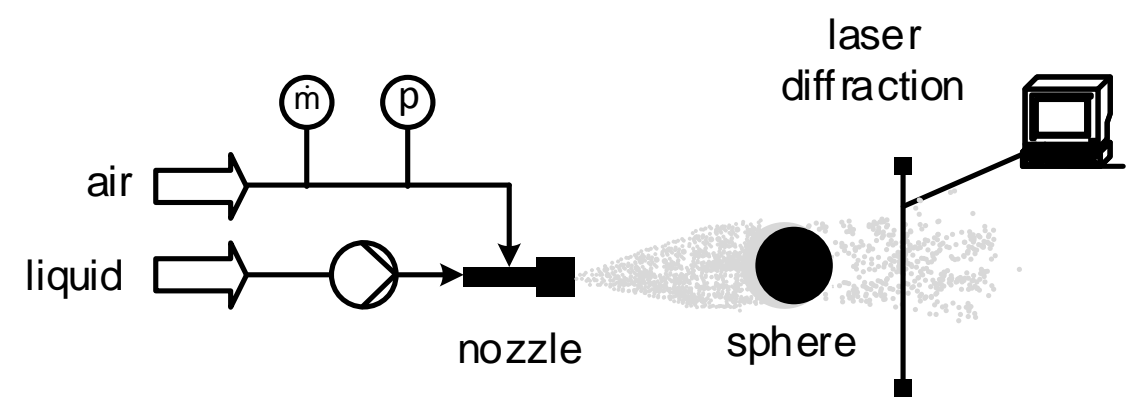

Figure 2: Experimental setup for spray fragmentation

A photograph shows the pneumatic nozzle with the impact sphere:

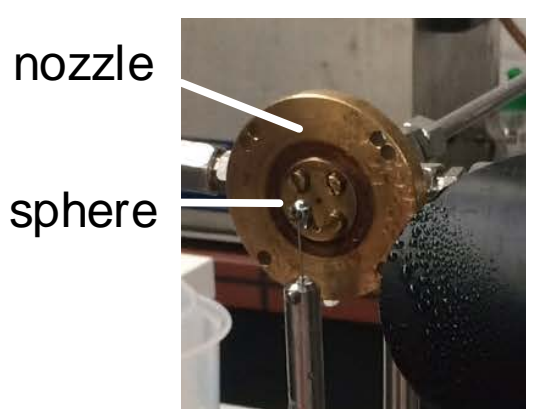

Figure 3: Photograph of the experimental setup for spray fragmentation

The droplet size distribution of the secondary aerosol was measured by laser diffraction technique (Spraytec, Malvern, Malvern, Worcestershire, United Kingdom). A lens focal length of $300 \mathrm{~mm}$ was used allowing for measurements of droplet sizes between 0.1-900 $\mu \mathrm{m}\left(d_{50,3}=0.5-600 \mu \mathrm{m}\right)$. The volumetric droplet size distribution was analysed. The distance between nozzle orifice and the laser beam was held constant at $8 \mathrm{~cm}$.

\section{Results and discussion}

For the primary and the secondary spray, the cumulative volumetric droplet size distribution and the volumetric droplet size distribution density is presented exemplarily for $\mu_{m}=0.25$ in Figure 4 .
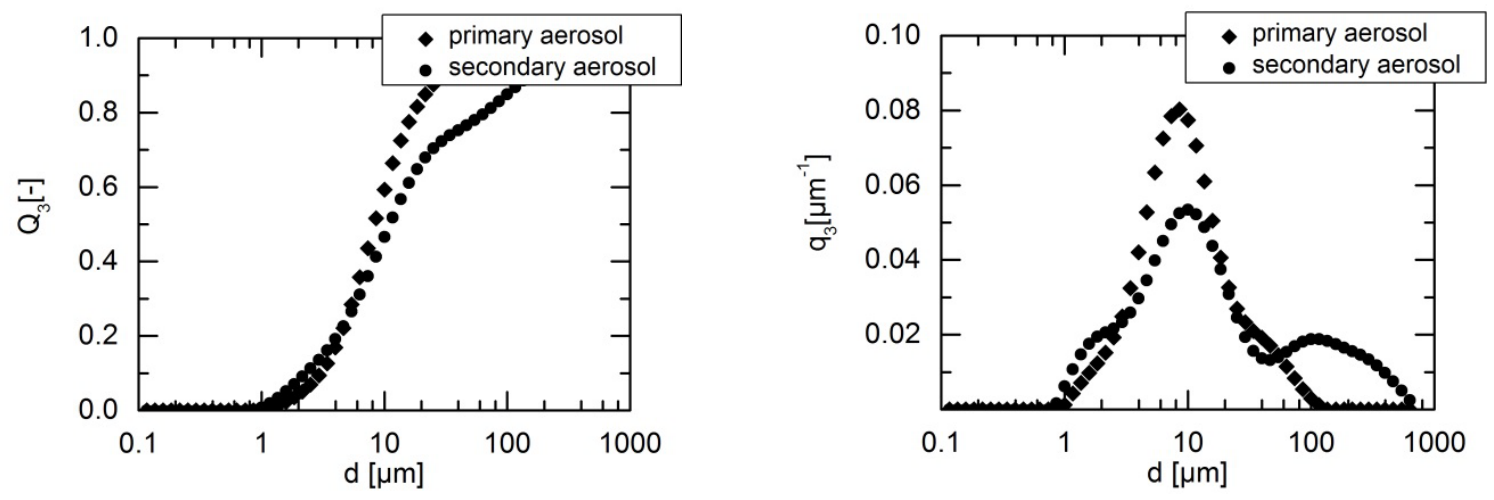

Figure 4: Cumulative (left) volumetric droplet size distribution and the volumetric droplet size distribution density (right) for the primary and the secondary aerosol. $\left(\mu_{m}=0.25\right)$

In Figure 5 the cumulative volumetric droplet size distribution is zoomed in for small droplet sizes.

This work is licensed under a Creative Commons 4.0 International License (CC BY-NC-ND 4.0). 


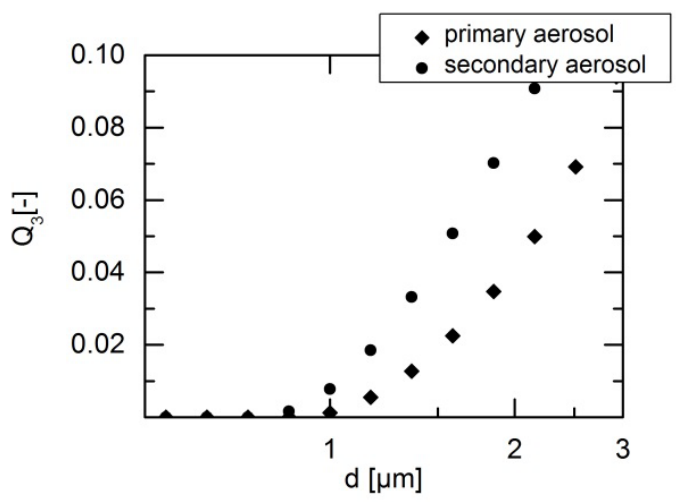

Figure 5: Detail view of the cumulative volumetric droplet size distribution for small droplets $\left(\mu_{m}=0.25\right)$

The secondary aerosol shows a slightly higher width of the distribution, thus generating also bigger droplets. Large droplets detach downward from the sphere and may be entrained by the gas flow. Additionally, a thin liquid layer is formed at the sphere during atomisation. Hence, secondary droplets are also formed from the layer due to the gas stream.

The amount of small droplets is increased upon impact. In Figure 6 the volumetric flowrate of droplets $<2 \mu m$ is presented as a function of the volumetric flowrate in the feed solution. A maximum flowrate of fine droplets was found at $\dot{V}_{\text {feed }}=40 \mathrm{~mL} / \mathrm{min}$ corresponding to a yield of about $2 \%$ of the total liquid flowrate. Further increased liquid flow rate decreases the amount of fines.

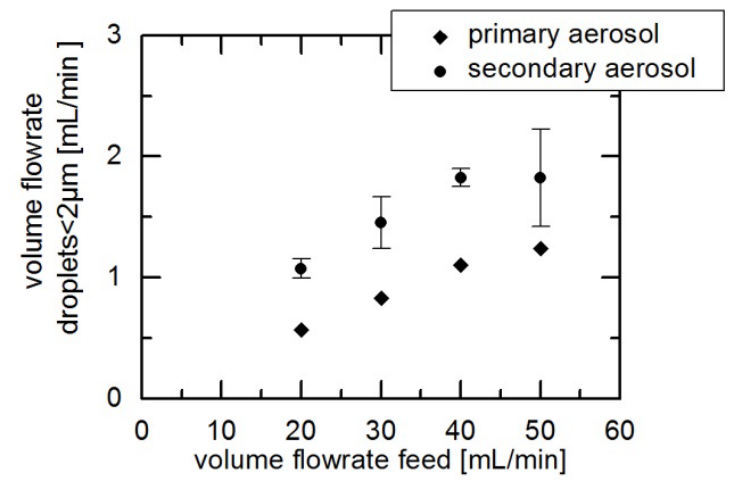

Figure 6:Volumetric flowrate of droplets $<2 \mu \mathrm{m}[\mathrm{mL} / \mathrm{min}]$ depending on the volumetric flowrate in the feed solution for the primary $(n=1)$ and the secondary aerosol $(\bar{x} \pm s d, n=3)$

The volumetric flowrate of droplets $<2 \mu \mathrm{m}$ was calculated from a cut of the cumulative volumetric droplet size distribution at $d=2 \mu m$ and reading the corresponding portion at the $y$-axis. This value is then multiplied with the total feed volumetric flow of the solution.

For the primary aerosol the absolute mass flow of small droplets increases with increasing volumetric feed flow. The amount of small droplets is increased due to fragmentation e.g. for $\dot{V}_{\text {feed }}=20 \mathrm{~mL} / \mathrm{min}$ from 0.5 (primary aerosol) to $1.1 \mathrm{~mL} / \mathrm{min}$ (secondary aerosol).

\section{Conclusions}

With the concept of aerosol conditioning, large droplets were separated from the primary aerosol before drying. The advantages of a robust pneumatic nozzle regarding to high solid concentrations and viscosities of the liquid is combined with a cyclone separator, generating a constant mean droplet size. This combination accomplishes all requirements of a system for industrial application in case of robustness, simplicity and long-term stability.

The volumetric amount of fine droplets separated depends on the characteristics of the pneumatic nozzle, since only $1 \%$ is in the suitable range of the primary aerosol. Therefore, in this work the primary aerosol is fragmented by positioning a sphere in front of the orifice. The geometry of a sphere was used to ensure uniform flow pattern of the spray after fragmentation. The amount of droplets $<2 \mu \mathrm{m}$ is increased for a liquid-to-gas mass flow ratio range of $0.24<\mu_{m}>0.7$ of about $100 \%$ from e.g. 0.5 to $1.1 \mathrm{~mL} / \mathrm{min}$. 
Furthermore, the phenomenon of spray impact on a sphere will be further investigated. Different geometric and fluid parameters will be varied and the effect on the droplet fragmentation will be analysed. During fragmentation, a liquid layer is formed on the sphere. The high gas velocity entrains the secondary droplets and leads to droplet detachment from the liquid film, thus generating also bigger droplets. This will be analysed with regard to the liquid loading.

After selection of the suitable geometric conditions for the smallest droplet size after fragmentation, the pneumatic nozzle with the impact sphere will be introduced into the cyclone droplet separator. The cyclone separation leads to a cut-off of the secondary aerosol, thus generating a narrow droplet size distribution with a small mean droplet size.

\section{Nomenclature}

A surface $\left[\mathrm{m}^{2}\right]$

C concentration $\left[\mathrm{kg} \mathrm{m}^{-3}\right]$

$c_{s} \quad$ saturation solubility nanosized API [ $\mathrm{kg} \mathrm{m}^{-3}$ ]

$C_{S}^{\infty} \quad$ saturation solubility of infinitely large API [ $\left.\mathrm{kg} \mathrm{m}^{-3}\right]$

$D \quad$ diffusion coefficient $\left[\mathrm{m}^{2} \mathrm{~s}^{-1}\right]$

d droplet size [m]

$d_{0} \quad$ droplet diameter before fragmentation [m]

$d_{50,3} \quad 50 \%$-quantile of the volumetric distribution [m]

$d_{\text {cut-off }}$ cut-off diameter of the cyclone [m]

$d_{\text {cap }} \quad$ inner capillary diameter [m]

$D_{0} \quad$ nozzle orifice diameter [m]

$d m / d t \quad$ dissolution rate $\left[\mathrm{kg} \mathrm{s}^{-1}\right]$

$h \quad$ diffusion layer thickness [m]

$M \quad$ molar mass $\left[\mathrm{kg} \mathrm{mol}^{-1}\right]$

$\dot{m}_{G} \quad$ gas mass flow $\left[\mathrm{kg} \mathrm{s}^{-1}\right]$

$\dot{m}_{L} \quad$ liquid mass flow $\left[\mathrm{kg} \mathrm{s}^{-1}\right]$

$\Delta p_{G} \quad$ pressure drop of the gas phase [Pa]

$Q_{3} \quad$ volumetric cumulative size distribution [-]

$R \quad$ gas constant $\left[\mathrm{J} \mathrm{mol}^{-1} \mathrm{~K}^{-1}\right]$

$r \quad$ particle radius [m]

$T \quad$ temperature [K]

$\dot{V} \quad$ volume flowrate $\left[\mathrm{m}^{3} \mathrm{~s}^{-1}\right]$

$v \quad$ collision velocity $\left[\mathrm{m} \mathrm{s}^{-1}\right]$

$V \quad$ interfacial tension [ $\left.\mathrm{J} \mathrm{m}^{-2}\right]$

$\eta \quad$ viscosity [mPas]

$\mu_{m} \quad$ liquid-to-air mass flow ratio $\left[\mathrm{kg}_{\text {liquid }} \mathrm{kg}_{\text {air }}{ }^{-1}\right]$

$\rho \quad$ density $\left[\mathrm{kg} \mathrm{m}^{-3}\right]$

\section{References}

[1] Okuyama, K., Wules Lenggoro, I., 2003, Chemical Engineering Science, 58, pp. 537-547

[2] Keck, C., Müller, R., 2006, European Journal of Pharmaceutics and Biopharmaceutics, 62, pp.3-16.

[3] Sosnik, A., 2015, Advances in Colloid and Interface Science, 223, pp. 40-54.

[4] Nernst W., 1904, Zeitschrift für Physikalische Chemie, 47(1), pp. 52-55.

[5] Brunner, E., 1904, Zeitschrift für Physikalische Chemie, 47(1), pp. 56-102.

[6] Wu, W., Nancollas, G., 1998, Journal of Solution Chemistry, 27(6), pp.521-531.

[7] Walzel, P., 1990, Chemie Ingenieur Technik, 62(12), pp. 983-994.

[8] Gorny, R., Schaldach, G., Walzel, P., Thommes, M., 4-7 Sep. 2016, ILASS - Europe, Brighton, UK

[9] Rein, M., 1993, Fluid Dynamics Research, 12, pp. 61-93.

[10] Walzel, P., 1980, Chemie Ingenieur Technik, 52 (4), pp. 338-339.

[11] Bakshi, S., Roisman, I., Tropea, C., 2007, Physics of Fluids, 19 (3), p. 32102 